OPEN ACCESS

Edited by:

Shannon D. Manning, Michigan State University,

United States

Reviewed by:

Saoussen Oueslati,

Institut National de la Santé et de la

Recherche Médicale (INSERM),

France

Barbara C Kahl,

University of Münster, Germany

${ }^{*}$ Correspondence: Abiola Senok

abiola.senok@mbru.ac.ae

${ }^{\text {t}}$ These authors have contributed equally to this work and share first authorship

Specialty section:

This article was submitted to Clinical Microbiology, a section of the journal Frontiers in Cellular and

Infection Microbiology

Received: 06 August 2021 Accepted: 13 September 2021

Published: 18 October 2021

Citation:

Senok A, Monecke S, Nassar $R$, Celiloglu H, Thyagarajan S, Müller E and Ehricht $R$ (2021) Lateral Flow Immunoassay for the Detection of

Panton-Valentine Leukocidin in

Staphylococcus aureus From

Skin and Soft Tissue Infections

in the United Arab Emirates.

Front. Cell. Infect. Microbiol. 11:754523.

doi: 10.3389/fcimb.2021.754523

\section{Lateral Flow Immunoassay for the Detection of Panton-Valentine Leukocidin in Staphylococcus aureus From Skin and Soft Tissue Infections in the United Arab Emirates}

\author{
Abiola Senok ${ }^{1 * t}$, Stefan Monecke ${ }^{2,3,4 t}$, Rania Nassar ${ }^{1,5}$, Handan Celiloglu ${ }^{1,6}$, \\ Sreeraj Thyagarajan ${ }^{6}$, Elke Müller ${ }^{2,3}$ and Ralf Ehricht ${ }^{2,3,7}$ \\ ${ }^{1}$ College of Medicine, Mohammed Bin Rashid University of Medicine and Health Sciences, Dubai, United Arab Emirates, \\ 2 Department of Optical Molecular Diagnostics and System Technology, Leibniz Institute of Photonic Technology (IPHT), \\ Jena, Germany, ${ }^{3}$ InfectoGnostics Research Campus, Jena, Germany, ${ }^{4}$ Institute for Medical Microbiology and Virology, \\ Dresden University Hospital, Dresden, Germany, ${ }^{5}$ Oral and Biomedical Sciences, School of Dentistry, Cardiff University, \\ Cardiff, United Kingdom, ${ }^{6}$ Department of Pathology \& Laboratory Medicine, Mediclinic City Hospital, Dubai, United Arab \\ Emirates, ${ }^{7}$ Institute of Physical Chemistry, Friedrich-Schiller University, Jena, Germany
}

Introduction: Panton Valentine leukocidin (PVL) is a virulence factor which is associated with methicillin sensitive and resistant Staphylococcus aureus (MSSA/MRSA) causing skin and soft tissue infections (SSTI). This study aimed to evaluate a novel lateral flow immunoassay (LFI) for PVL detection in $S$. aureus cultures and to describe their genotypic characterization.

Methods: The study was carried out from January-August 2020 in Dubai, United Arab Emirates. S. aureus isolates associated with SSTI were tested for PVL detection using LFI. DNA microarray-based assays were used for molecular characterization including detection of $p v /$ genes.

Results: One-hundred thirty-five patients with a clinical diagnosis of SSTIs were recruited. Sixty-six patients received antibiotics, mostly beta lactams $(n=36)$ and topical fusidic acid $(n=15)$. One-hundred twenty-nine isolates (MRSA: $n=43$; MSSA: $n=86$ ) were tested by LFI and DNA microarrays. All 76 (58.9\%) isolates which were unambiguously negative for the PVL in LFI were negative for pvl genes using the DNA microarray. All the LFI PVL positive isolates $(n=53)$ had pvl genes detected. This translates into 100\% each for sensitivity, specificity, positive and negative predictive values for the LFI. The LFI typically takes about 15 min inclusive of a 10 min incubation period. Predominant $S$. aureus clonal complexes (CC) were CC30 ( $n=18), \operatorname{CC} 22(n=13), \operatorname{CC5}(n=12), \operatorname{CC1}(n=11), \operatorname{CC152}(n=8), \operatorname{CC15}$ $(n=7)$; CC97 $(n=7)$; CC8 and CC20 ( $n=6$ each). Among MRSA, the proportion of pvlpositives (35/43; 81\%) was higher than among MSSA ( $\mathrm{n} / \mathrm{N}=18 / 86 ; 21 \%)$. The fusidic acid resistance gene fusC was detected in 14 MRSA (33\%) compared to 8 MSSA (9\%). A cocarriage of fusC and pvl genes was present in 7 MRSA and in one MSSA. 
Conclusion: LFI shows excellent diagnostic accuracy indices for rapid identification of PVL in MSSA/MRSA in a setting with high prevalence of $p v l^{+v e}$ strains. The high occurrence of $\mathrm{pvl}$ and fusC genes in MRSA strains causing SSTI is of concern and needs constant surveillance.

Keywords: lateral flow immunoassay, Staphylococcus aureus, Panton Valentine leucocidin, skin and soft tissue infection, DNA microarray

\section{INTRODUCTION}

Methicillin sensitive and resistant Staphylococcus aureus (MSSA/ MRSA) are aetiological agents of chronic/recurrent skin and soft tissue infections (SSTI). The spectrum of infections which may be community or hospital acquired range from impetigo and folliculitis to more serious surgical site infections. Global data indicates an increasing trend of incidence and severity of SSTIs caused by MRSA isolates (Olaniyi et al., 2017). Panton Valentine leukocidin (PVL) is a virulence factor which is associated with $S$. aureus strains causing SSTI and severe forms of community acquired pneumonia (Gosbell, 2005; Wannet et al., 2005; Yamasaki et al., 2005; Marazza et al., 2007; Masiuk et al., 2010; Gillet et al., 2021). PVL consists of two distinct components which form polymeric pores in the membranes of white blood cells which leads to cell death. This might explain the higher risk of complicated SSTI infection associated with PVL positive S. aureus strains (Szmigielski et al., 1998; Kaneko and Kamio, 2004). The $p v l$ genes, lukS-PV and lukF-PV, are phage borne (Narita et al., 2001; Boakes et al., 2011), and since they are mobile, they can be found in different, unrelated lineages of $S$. aureus (Monecke et al., 2007; Monecke et al., 2011a).

Detection of $p v l$ genes in S. aureus is usually done by molecular methods and is not routinely offered by most diagnostic laboratories. Findings from a meta-analysis report suggests that PVL-producing S. aureus are associated with SSTIs with increased risk for surgical intervention (Shallcross et al., 2013). In light of this, a rapid and affordable method for the identification of PVL in $S$. aureus strains isolated from SSTI, which can be carried out without the need for expensive molecular assays is desirable for the diagnostic microbiology laboratory.

This is particularly pertinent in settings such as the Arabian Gulf region with high prevalence of $p v l^{+\mathrm{ve}} S$. aureus (Senok et al., 2016b; Senok et al., 2019b; Senok et al., 2020a). The countries of the Arabian Gulf region are a global hub for travel and commerce with tourists, pilgrims, and expatriate workers from all across the world. This includes regions from which nothing is known on MSSA/MRSA prevalence and $S$. aureus population structure. Indeed, with the cosmopolitan character of the United Arab Emirates (UAE) and reported high biodiversity of MSSA and MRSA including high prevalence of strains with $p v l$ genes, it represents a suitable study setting with regard to $S$. aureus toxins and typing (Senok et al., 2020a; Senok et al., 2020b).

In this study, we describe the application of a novel lateral flow immunoassay for rapid PVL detection in S. aureus directly from bacterial cultures and in addition, we present data on the molecular characterization of a collection of MSSA/MRSA strains associated with SSTI.

\section{METHODS}

\subsection{Study Site}

The study was carried out from January-August 2020 at Mediclinic hospitals and clinics in Dubai, United Arab Emirates. S. aureus isolates studied were those associated with SSTI and identified as part of routine diagnostics in the microbiology laboratory during the study period. Only isolates from patients with diagnosis of furunculosis or carbuncles, cutaneous abscesses; or other conspicuous or severe skin and soft tissue infections such as mastitis or necrotising fasciitis; chronically purulent and painful "spider bites"; recurrent or chronic skin- and soft tissue infections were eligible for inclusion. Demographic and clinical data including age, gender, history of recurrence, animal contact, insect bite, travel history and antibiotic use were obtained.

\subsection{Bacterial Isolates}

Only one isolate per patient was included. In a single case, two genotypically different isolates from one sample were considered. $S$. aureus isolates obtained from screening samples (nasal, buccal, axillary, rectal swabs), from diabetic foot ulcers and for other clinical indications were excluded. Identification of $S$. aureus, confirmation of methicillin resistance and antibiotic susceptibility testing were carried using the VITEK 2 automated platform (bioMérieux, Marcy-l'Étoile, France) in accordance to manufacturer's instructions and Clinical and Laboratory Standards Institute guidelines (CLSI, 2017). Isolates meeting the inclusion criteria were studied for lateral flow immunoassay and molecular characterization. Ethical approval was obtained from Mohammed Bin Rashid University, and Mediclinic Hospitals ethics committees (MBRU-IRB-2020-003 and MCME.CR.98.MCIT.2020).

\subsection{Lateral Flow Immunoassay}

\subsubsection{Principle of the Test}

The core of the lateral flow immunoassay consists of a porous nitrocellulose membrane on which PVL-specific antibodies are immobilized. The antibodies were generated using conventional method using mouse hybridoma cells, and the immunization was performed with recombinant lukF-PV that was produced as previously described (Köhler and Milstein, 2005; Stieber et al., 2014). In addition to the nitrocellulose membrane, other differently functional, successively overlapping membranes are fixed on a self-adhesive plastic card (Figure 1). These membranes enable the migration of the soluble proteins from the culture material through the porous structures. Before the sample migrates through the nitrocellulose membrane, it is 
applied to a sample pad, which ensures even distribution and pre-treatment of the sample. The sample is transported from the sample pad to the adjoining conjugate pad, into which PVLspecific antibodies labeled with dyed particles have been introduced. These conjugates bind specifically to PVL in the sample and are required for visualization on the test line. From there, the complexes comprising dyed particles, antibodies and PVL molecules are led into the nitrocellulose membrane, on which a colored band is generated by analyte enrichment due to the immobilized PVL-specific antibodies, which capture the complexes. Not bounded dyed particle conjugates bind to a second line on the nitrocellulose membrane and form a second reaction-independent control that indicates the functionality of the test. Finally, the sample is passed on to the wicking pad located behind the control zone and picked up there to prevent backflow. The appearance of a visual test band indicates a positive result, and the absence of the test band indicates a negative result. The test is considered invalid if the control band does not appear (Figure 1).

\subsubsection{Lateral Flow Immunoassay Tests}

$S$. aureus isolates meeting the inclusion criteria were sub-cultured on Columbia Blood Agar, incubated overnight or up to $24 \mathrm{hrs}$ at $37^{\circ} \mathrm{C} \pm 2^{\circ} \mathrm{C}$. Fresh (overnight to 24 hours) cultures were used for the test. One inoculation loop $(\geq \sim 10 \mu \mathrm{l})$ full of culture material was inoculated into $300 \mu \mathrm{l}$ of the kit buffer and vortexed for 15-30 sec until cell suspension was homogenous. The buffer with the suspended inoculum was centrifuged at 2,000 $\mathrm{g}$ for $30 \mathrm{sec}$, then $100 \mu \mathrm{l}$ of the supernatant was pipetted onto the sample well of the test device, incubated for $10 \mathrm{~min}$ at room temperature. The appearance of the visual test band was noted and the image of the result on the lateral flow device was photographed. The appearance of a visual test band indicates a positive result, its absence is indicative of a negative result and the test is considered invalid if the control band does not appear. The image of the test result was independently reviewed by two researchers (S.M \& R.E) who were blinded to the DNA microarray result.

\subsection{DNA Microarray}

Molecular characterization was carried out using the StaphyType DNA microarray (Abbott [Alere Technologies GmbH], Jena, Germany) and the INTER-ARRAY Genotyping Kit S.aureus (Inter-Array $\mathrm{GmbH}$, Bad Langensalza, Germany) for the detection of species markers as well as of virulence and resistance genes. The previously described probes, primers, and procedures were used (Monecke et al., 2011a; Monecke et al., 2011b; Monecke et al., 2016). SCCmec subtyping using a second array was carried out on selected isolates as previously described (Monecke et al., 2016). Microarray images were taken, and analysis was carried out using the dedicated reader and software (Alere Technologies) as previously described (Monecke et al., 2011a; Monecke et al., 2011b; Monecke et al., 2016). The microarray harbored probes for both, $l u k S-P V$ and lukF-PV thus facilitating molecular confirmation of the lateral flow immunoassay.

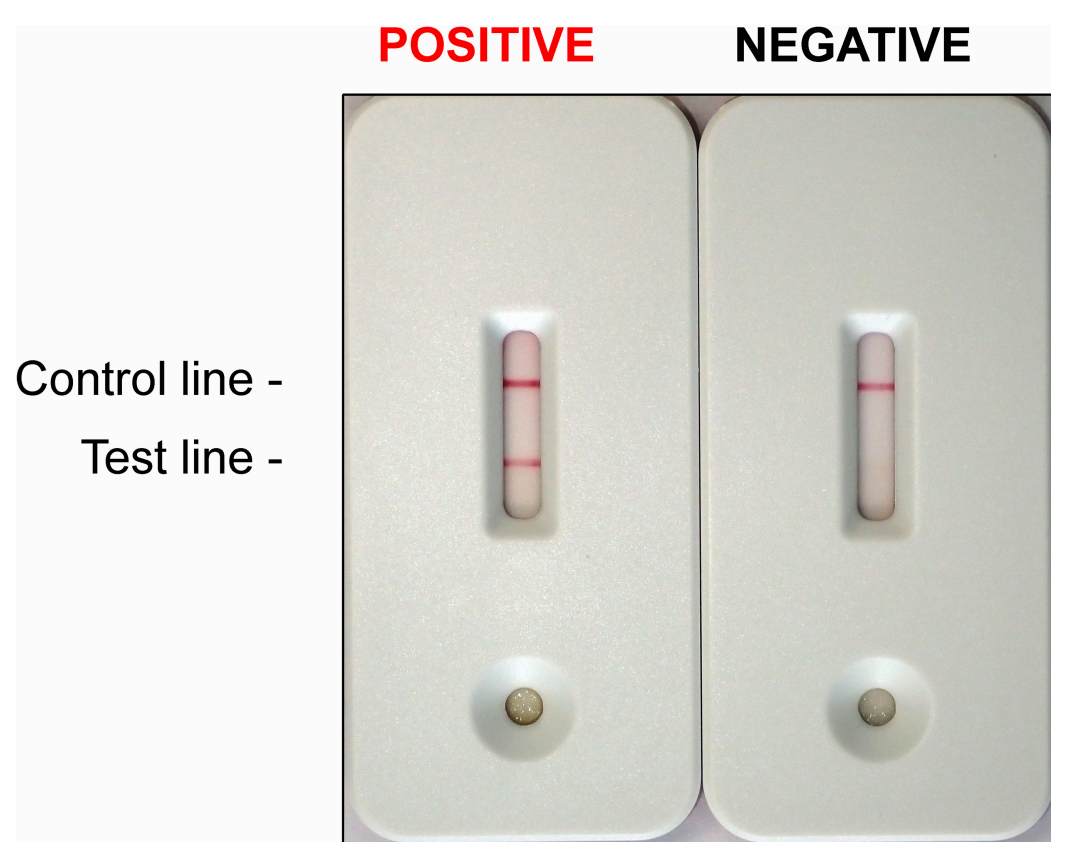

FIGURE 1 | Staphylococcus aureus Panton Valentine leukocidin Lateral Flow Immunoassay. A positive and a negative test. Lines must appear within 10 min of incubation at room temperature. Red lines appearing in the TEST line region (TEST) and in the CONTROL line region (CONTROL) indicate together a POSITIVE result (LEFT). The TEST line can be weaker than the CONTROL line. A red line appearing in the CONTROL line region (CONTROL) serves as the internal control. It confirms sufficient sample volume and correct procedural technique. If the CONTROL line was absent, the test is to be regarded as INVALID and should be repeated. A clear background is also required. If only the CONTROL line appears (RIGHT), the test is NEGATIVE. 


\section{RESULTS}

A total of 135 patients were recruited with mean age ( \pm SD) 27.7 ( \pm 17.9$)$ years and majority $(n=71)$ were females. Most of the patients $(n=130)$ were from the outpatient setting and $20.7 \%(n /$ $\mathrm{N}=28 / 135$ ) gave a history of recurrent skin infections. None of the patients reported similar infections in family members. Clinical diagnoses among the patients were mostly cutaneous abscesses $(n=41)$; folliculitis/furuncle/impetigo $(n=35)$ and secondary infections of underlying dermatological conditions $(n=35)$. The information regarding history of animal contact was available for only 25 participants, and all of them reported that they had no animal contact. Sixty-six patients were treated with antibiotics with a majority $(\mathrm{n} / \mathrm{N}=36 / 66)$ receiving beta lactam drugs mainly amoxicillin-clavulanic acid $(n=26)$, cefuroxime $(n=6)$ or ceftriaxone $(n=4)$. Fifteen patients received topical fusidic acid. Table 1 shows the details of the demographic and clinical profiles of the patients.

\subsection{Lateral Flow Immunoassay}

After exclusion of negative cultures and duplicate strains, a total of 129 isolates (MRSA: $n=43$; MSSA: $n=86$ ) were tested by lateral flow immunoassay. Of these, 76 (58.9\%) were unambiguously negative for PVL and these were the same isolates which were also negative for $p v l$ genes as determined by DNA microarray. All 53 isolates which were positive using the lateral flow assay also had $p v l$ genes detectable by DNA microarray. Using the molecular detection as gold standard, this translates into $100 \%$ each for diagnostic sensitivity, specificity and positive and negative predictive values of the lateral flow immunoassay. There were four isolates which yielded weak positive signals on the lateral flow immunoassay. Assuming that these could be misread as negative by unexperienced or distracted users in a real-life setting, a diagnostic sensitivity of $92.5 \%$, a negative predictive value of $95 \%$ as well as specificity and positive predictive value of $100 \%$ can be expected. The test typically takes about $15 \mathrm{~min}$ inclusive of $10 \mathrm{~min}$ incubation period.

\subsection{Molecular Characterization of $S$. aureus Isolates}

All 129 isolates were successfully characterized and assigned to clonal complexes and strains. There was a wide clonal diversity with isolates being assigned to 28 clonal complexes (CC) and 58 strains (Table 2). The predominant CC were CC30 ( $\mathrm{n}=18), \mathrm{CC} 22$ $(n=13), \operatorname{CC} 5(n=12), \operatorname{CC} 1(n=11), \operatorname{CC} 152(n=8), \operatorname{CC} 15(n=7)$; CC97 $(n=7)$ as well as CC8 and CC20 ( $n=6$ each) (Table 2). One isolate was determined to be Staphylococcus argenteus CC2696. The MRSA isolates were predominantly CC22 $(n=11)$, CC30 $(\mathrm{n}=12)$ and CC5 $(=8)$.

Table 3 shows the distribution of virulence and antibiotic resistance genes in the isolates characterized. Commonly identified virulence genes were the $p v l$ genes $l u k S-P V$ and $l u k F-$ $P V$, toxic shock syndrome toxin $1(t s t 1)$ and various enterotoxin

TABLE 1 | Demographic and Clinical Profile of patients with skin and soft tissue infections.

\begin{tabular}{|c|c|c|c|}
\hline Total number of patients & & & $N=135$ \\
\hline Age $($ mean $\pm \mathrm{SD})$ & & & $\begin{array}{c}27.7( \pm 17.9) \text { years } \\
\mathrm{n}(\%)\end{array}$ \\
\hline \multirow[t]{2}{*}{ Gender } & Male & & $64(47.4 \%)$ \\
\hline & Female & & $71(52.6 \%)$ \\
\hline \multicolumn{4}{|l|}{ Clinical diagnosis } \\
\hline & Cutaneous/subcutaneous abscess & & $41(30.4 \%)$ \\
\hline & Folliculitis/furuncle/impetigo & & $35(25.9 \%)$ \\
\hline & Secondary infection of underlying dermatological condition & & $35(25.9 \%)$ \\
\hline & Cellulitis & & $14(10.4 \%)$ \\
\hline & Wound infection & & $10(7.4 \%)$ \\
\hline \multirow[t]{7}{*}{ Recent antibiotic use } & & & $24(17.8 \%)$ \\
\hline & Antibiotics & $n$ & \\
\hline & Beta lactams & 10 & \\
\hline & Fusidic acid & 6 & \\
\hline & Fluoroquinolones & 2 & \\
\hline & Unknown & 2 & \\
\hline & Vancomycin, Mupirocin, Tetracycline, Erythromycin & $n=1$ each & \\
\hline Recent travel history & & & $6(4.4 \%)$ \\
\hline Recent inset bite & & & $4(2.9 \%)$ \\
\hline \multirow[t]{8}{*}{ Treatment with antibiotics } & & & 66 (48.9\%) \\
\hline & Antibiotics & $n$ & \\
\hline & Beta lactams & 36 & \\
\hline & Fusidic acid & $15^{\star}$ & \\
\hline & Macrolides & 10 & \\
\hline & Mupirocin & $5^{\star *}$ & \\
\hline & Fluroquinolones & 4 & \\
\hline & Tetracyclines & 4 & \\
\hline Staphylococcus aureus & Methicillin susceptible S. aureus (MSSA) & & $86(66.7 \%)$ \\
\hline identified ( $\mathrm{N}=129)$ & Methicillin resistant $S$. aureus (MRSA) & & $43(33.3 \%)$ \\
\hline Outcome & Recovered & & $135(100 \%)$ \\
\hline
\end{tabular}

${ }^{*} 6$ patients received fusidic acid in combination with either a beta lactam, macrolide or tetracycline **2 patients received mupirocin in combination with a macrolide. 
TABLE 2 | Distribution of clonal complexes and strain assignment.

Total number of isolates characterized by DNA Microarray: 129

\begin{tabular}{|c|c|c|c|}
\hline Clonal complex & Number of isolates (\%) & Strain Assignment & Number of isolates (\%) \\
\hline \multirow[t]{5}{*}{ CC1 } & $11(8.5 \%)$ & CC1-MSSA & $3(2.3 \%)$ \\
\hline & & CC1-MSSA (PVL+) & $1(0.8 \%)$ \\
\hline & & CC1-MSSA-[fusC+ccrAB1] & $5(3.9 \%)$ \\
\hline & & CC1-MSSA-[fusC+ccrAB1] (PVL+) & $1(0.8 \%)$ \\
\hline & & CC1-MRSA-[IV+fusC+CcrAB1], WA MRSA-1/45 & $1(0.8 \%)$ \\
\hline \multirow[t]{6}{*}{ CC5 } & $12(9.3 \%)$ & CC5-MSSA & $2(1.6 \%)$ \\
\hline & & CC5-MSSA (PVL+) & $1(0.8 \%)$ \\
\hline & & CC5-MSSA-[fusC+ccrC] & $1(0.8 \%)$ \\
\hline & & CC5-MRSA-[VNT+fusC] (PVL+) & $3(2.3 \%)$ \\
\hline & & CC5-MRSA-[VNT+fusC] (sed/j/r-) & $4(3.1 \%)$ \\
\hline & & CC5-MRSA-IV (PVL+/edinA+), WA MRSA-003/-121 & $1(0.8 \%)$ \\
\hline \multirow[t]{3}{*}{ CC6 } & $3(2.3 \%)$ & CC6-MSSA & $1(0.8 \%)$ \\
\hline & & CC6-MSSA-[fusC+ccrC] & $1(0.8 \%)$ \\
\hline & & CC6-MRSA-IV, WA MRSA-51 & $1(0.8 \%)$ \\
\hline CC7 & $4(3.1 \%)$ & CC7-MSSA & $4(3.1 \%)$ \\
\hline \multirow[t]{3}{*}{ CC8 } & $6(4.7 \%)$ & CC8-MSSA & $3(2.3 \%)$ \\
\hline & & CC8-MSSA-[kdp+bap] & $1(0.8 \%)$ \\
\hline & & CC8-MRSA-[IV+ACME] (PVL+), USA300 & $2(1.6 \%)$ \\
\hline CC10 & $1(0.8 \%)$ & CC10-MSSA & $1(0.8 \%)$ \\
\hline \multirow[t]{3}{*}{ CC15 } & $6(4.7 \%)$ & CC15-MSSA & $4(3.1 \%)$ \\
\hline & & CC15-MSSA (PVL+) & $1(0.8 \%)$ \\
\hline & & CC15-MRSA-[VNT+fusC] & $1(0.8 \%)$ \\
\hline CC15 (ST199) & $1(0.8 \%)$ & CC15 (ST199)-MSSA & $1(0.8 \%)$ \\
\hline CC20 & $6(4.7 \%)$ & CC20-MSSA & $6(4.7 \%)$ \\
\hline \multirow[t]{3}{*}{$\mathrm{CC} 22$} & $13(10.1 \%)$ & CC22-MSSA & $2(1.6 \%)$ \\
\hline & & CC22-MRSA-IV (PVL+) & $4(3.1 \%)$ \\
\hline & & CC22-MRSA-IV (PVL+/tst+) & $7(5.4 \%)$ \\
\hline CC25 & $1(0.8 \%$ & CC25-MSSA & $1(0.8 \%)$ \\
\hline \multirow[t]{4}{*}{ Сс30 } & $18(14.0 \%)$ & CC30-MSSA & $6(4.7 \%)$ \\
\hline & & CС30-MSSA (PVL+) & $3(2.3 \%)$ \\
\hline & & CC30-MRSA-IV (PVL+), "WSPP/Southwest Pacific Clone" & $7(5.4 \%)$ \\
\hline & & CC30-MRSA-[VI+fusC] (PVL+) & $2(1.6 \%)$ \\
\hline CC45 [agr l] & $2(1.6 \%)$ & CC45-MSSA & $2(1.6 \%)$ \\
\hline CC80 & $1(0.8 \%)$ & CC80-MRSA-IV (PVL+) & $1(0.8 \%)$ \\
\hline \multirow[t]{2}{*}{$\operatorname{Cc97}$} & $7(5.4 \%)$ & CC97-MSSA & $6(4.7 \%)$ \\
\hline & & CC97-MRSA-[VNT+fusC] & $1(0.8 \%)$ \\
\hline CC101 & $1(0.8 \%)$ & CC101-MSSA & $1(0.8 \%)$ \\
\hline \multirow[t]{2}{*}{ CC121 } & $5(3.9 \%)$ & CC121-MSSA & $4(3.1 \%)$ \\
\hline & & CC121-MRSA-VNT (PVL+) & $1(0.8 \%)$ \\
\hline \multirow[t]{2}{*}{ CC152 } & $8(6.2 \%)$ & CC152-MSSA (PVL+) & $7(5.4 \%)$ \\
\hline & & CC152-MRSA-IV (PVL+) & $1(0.8 \%)$ \\
\hline CC182 & $1(0.8 \%)$ & CC182-MSSA & $1(0.8 \%)$ \\
\hline CC188 & $2(1.6 \%)$ & CC188-MSSA (PVL+) & $2(1.6 \%)$ \\
\hline CC361 & $1(0.8 \%)$ & CC361-MSSA & $1(0.8 \%)$ \\
\hline \multirow[t]{2}{*}{ CC398 } & $2(1.6 \%)$ & CC398-MSSA & $1(0.8 \%)$ \\
\hline & & CC398-MRSA-VNT (PVL+) & $1(0.8 \%)$ \\
\hline \multirow[t]{2}{*}{ CC398 (ST291/813) } & $2(1.6 \%)$ & ST291/813-MSSA & $1(0.8 \%)$ \\
\hline & & ST291/813-MSSA (PVL+) & $1(0.8 \%)$ \\
\hline \multirow[t]{2}{*}{ CC772 } & $4(3.1 \%)$ & CC772-MSSA (PVL+) & $1(0.8 \%)$ \\
\hline & & CC772-MRSA-VNT (PVL+), "Bengal Bay Clone" & $3(2.3 \%)$ \\
\hline \multirow[t]{3}{*}{ CC1153 } & $3(2.3 \%)$ & CC1153-MSSA & $1(0.8 \%)$ \\
\hline & & CC1153-MRSA-PseudoSCCmec [class B+fusC+ccrAB1] (PVL+) & $1(0.8 \%)$ \\
\hline & & CC1153-MRSA-[VNT+fusC] (PVL+) & $1(0.8 \%)$ \\
\hline ST1156 & $1(0.8 \%)$ & ST1156-MSSA & $1(0.8 \%)$ \\
\hline CC2531 & $1(0.8 \%)$ & ST2816-MSSA & $1(0.8 \%)$ \\
\hline ST2867 & $3(2.3 \%)$ & ST2867-MSSA & $3(2.3 \%)$ \\
\hline CC2990 & $2(1.6 \%)$ & CC2990-MSSA & $2(1.6 \%)$ \\
\hline Staphylococcus argenteus CC2596 & $1(0.8 \%)$ & CC2596-MSSA & $1(0.8 \%)$ \\
\hline
\end{tabular}

MSSA, Methicillin sensitive Staphylococcus aureus; MRSA, Methicillin resistant Staphylococcus aureus. 
genes, $S$. aureus surface protein $\mathrm{G}(\mathrm{sas} G)$ and epidermal cell differentiation inhibitor $B(e d i n B)$ genes. Most of the MRSA strains $(35 / 43 ; 81 \%)$ harbored the lukS-PV and $l u k F-P V$ genes. This was a much higher proportion compared to MSSA, out of which 18 isolates (21\%) were positive for $l u k S-P V$ and $l u k F-P V$ genes. The fusidic acid resistance gene fusC was detected in 14 MRSA (33\%) strains while only 8 MSSA (9\%) were positive for this gene, 7 MRSA (CC5, CC30, CC1153) carried both, fusC and $p v l$ genes. This combination was seen only once among MSSA (CC1). The mupirocin resistance (mupA) gene were detected in four strains (MSSA/MRSA: $n=2$ each) and none of the isolates was found to carry vancomycin resistance genes.

\section{DISCUSSION}

We present the first report on the application of a novel lateral flow immunoassay for PVL detection in S. aureus isolates in a setting with wide MSSA/MRSA clonal diversity and high prevalence of $p v l^{+\mathrm{ve}}$ strains. Using well-established DNA microarray-based assays for molecular detection of $p v l$ genes as the gold standard, the findings show that the lateral flow immunoassay demonstrates excellent diagnostic accuracy indices. There was full concordance in $p v l$ detection by the lateral flow immunoassay and the molecular confirmatory method used. As previously reported, the in vitro expression of PVL varies widely depending on CC affiliation of the $S$. aureus strain and the presence of other virulence genes (Stieber et al., 2014). This could explain the weak positive signals observed for four isolates. The $100 \%$ diagnostic sensitivity and specificity we have documented is of significance as this study was carried out in the context of a setting characterized by high prevalence of $p v l^{+v e}$ strains. Two similar assays have previously been reported that yielded similar high diagnostic accuracy indices using strains obtained from various countries (Badiou et al., 2010; Monecke et al., 2013). Unfortunately, these assays were eventually not marketed by the respective companies so the need for an easy, non-molecular culture confirmation test remained unaddressed. Our findings show that despite the remarkable evolution of $S$. aureus genotypes in recent years, the lateral flow immunoassay for PVL detection still yields excellent diagnostic results. This could be attributed to the rare occurrence of sequence variations in $p v l$ genes. As these genes face a selective pressure to maintain their function in presence of the host's defenses, a significant degree of conservation is to be expected (O'hara et al., 2008; Boakes et al., 2011). The lateral flow immunoassay is rapid, easy to use and interpret, and is highly economical making it ideal for diagnostic microbiology laboratories worldwide. It will be particularly beneficial in diagnostic laboratories serving primary care facilities where majority of patients with SSTIs are first seen (Ramakrishnan et al., 2015). Several countries in the developing world have reported a high prevalence of $p v l^{+\mathrm{ve}} S$. aureus strains and this lateral flow assay will be optimal in such resource limited settings where access to molecular assays may be lacking (Rasigade et al., 2010; Monecke et al., 2014; Abdulgader et al., 2015; Rasigade et al., 2015). With the potential threat of poor clinical outcomes associated with $p v l^{+v e} S$. aureus strains, their early identification is crucial particularly in settings such as ours where $S$. aureus strains harboring $p v l$ genes are circulating widely (Szmigielski et al., 1998; Kaneko and Kamio, 2004; Shallcross et al., 2013; Senok et al., 2020a). In this study, most of the patients had presentations consistent with mild SSTIs (Ramakrishnan et al., 2015) and majority received antibiotics with beta lactams and fusidic acid being the most prescribed antibiotics. According to current guidelines, mild purulent SSTIs in easily accessible sites with minimal cellulitis can be treated by incision and drainage alone, without a need for antibiotics (Public Health England, 2008; Gillet et al., 2011; Ramakrishnan et al., 2015). However, an antimicrobial coverage to mitigate against a potential threat of complications occurs commonly thus contributing to antibiotic misuse. The widespread utilization of beta lactams and fusidic acid in SSTI is a likely contributory factor to the emergence of resistance to these antibiotics resulting in the high occurrence of MRSA strains with SCCmec + SCCfusC composite elements in the Arabian Gulf region (Senok et al., 2020a; Monecke et al., 2021). The continued evolution and upward trend of MRSA in the region has been linked to strains harboring these composite elements (Senok et al., 2020a; Monecke et al., 2021). Hence, the high prevalence of MRSA isolates associated with SSTI, as well as the rate of detection of isolates harboring $p v l$ and $f u s C$ genes is worrisome. The presence of co-carriage of $p v l$ and fus $C$ genes was found more commonly in MRSA compared to MSSA strains which is in keeping with reports of other studies from the same geographic region (Monecke et al., 2012b; Senok et al., 2016b; Boswihi et al., 2018; Senok et al., 2019b; Senok et al., 2020a). Therefore, it is envisaged that the incorporation of this lateral flow immunoassay in the diagnostic workflow will enable microbiology laboratories to provide clinicians with information on the PVL status of the MSSA/MRSA isolates identified from bacterial cultures of SSTIs which would be helpful in guiding physicians towards rational choices that support judicious use of antibiotics.

It is noteworthy that in contrast to other studies, the findings from this study provide a unique insight into the molecular epidemiology of $S$. aureus strains causing SSTIs in our setting. These strains harbor a diversity of antibiotic resistance genes including mecA, fus $C$, aacA-aphD and in addition to $p v l$ they also carry important toxin virulence genes notably tst-1, edin $B$, et $A$ and various enterotoxin genes. In the UAE and countries of the Arabian Gulf region, MRSA contributes significantly to the burden of clinical infections and most of the MRSA strains detected in this study are those that have previously been observed in the region (Senok et al., 2016a; Boswihi et al., 2018; Senok et al., 2020a). Although wide clonal and strain diversity was evident with 19 different MRSA strains belonging to 14 different clonal complexes identified, unlike other reports no novel variants were found in this study. Some of the strains identified have also been detected in other parts of the world which suggests the role of a dynamic population movement in facilitating either importation into the UAE, or dissemination to other countries by returnees.

Our findings demonstrate the contribution of well-known pandemic and regionally restricted as well as rare MRSA strains 
TABLE 3 | Distribution of virulence and antibiotic resistance gene markers.

Selection of gene markers/cluster

\# positive ( $\mathrm{N}=129)$

$\%$ positive

Antibiotic resistance genes/locus

Alternate penicillin binding protein 2, defining MRSA

Mercury resistance operon

Cassette chromosome recombinase $\mathrm{A} / \mathrm{B}$, type 1

Cassette chromosome recombinase $A / B$, type 2

Cassette chromosome recombinase $A / B$, type 3

Cassette chromosome recombinase $A A / C$

Cassette chromosome recombinase A/B, type 4

scCmec XI

Truncated methicillin resistance operon repressor 1

Beta-lactamase operon

rRNA adenine N-6-methyl-transferase, erythromycin/clindamycin resistance

Erythromycin/clindamycin resistance

Erythromycin/clindamycin resistance

Lincosamide Nucleotidyltransferase

Energy-dependent efflux of erythromycin

Macrolide efflux protein A

Lysylphosphatidyl glycerol synthetase

Bifunctional enzyme gentamicin resistance

Amino-glycoside adenyl-transferase,tobramycin resistance

3'5'-aminog-lycoside phospho-transferase, neo-/kanamycin resistance

Streptothricine acetyltransferase

Dihydrofolate reductase type 1

Hypothetical protein associated with fusidic acid resistance

Mupirocin resistance protein

Tetracycline resistance

Tetracycline resistance

Chloramphenicol acetyltransferase

23S rRNA methyltransferase

Chloramphenicol/florfenicol exporter

Quaternary ammonium compound resistance protein $A / B$

Quaternary ammonium compound resistance protein A/B

Vancomycin resistance genes

Teicoplanin resistance gene from enterococci

Virulence genes

Toxic shock syndrome toxin 1

Panton Valentine leukocidin F/S component

Accessory gene regulator I

Accessory gene regulator II

Accessory gene regulator III

Accessory gene regulator IV

Capsule type 5

Capsule type 8

Exfoliative toxin serotype $A$

Exfoliative toxin serotype $B$

Enterotoxin A

Enterotoxin A, allele from strain 320E

Enterotoxin A, allele from strain N315 (Enterotoxin P)

Enterotoxin B

Enterotoxin C

Enterotoxin C

Enterotoxin $\mathrm{E}$

Enterotoxin $\mathrm{H}$

Enterotoxin J

Enterotoxin $\mathrm{K}$

Enterotoxin L

Enterotoxin Q

Enterotoxin $\mathrm{R}$

Enterotoxin gene cluster (total)

Enterotoxin-like protein ORF CM14

Exfoliative toxin D

Epidermal cell differentiation inhibitor A

Epidermal cell differentiation inhibitor B

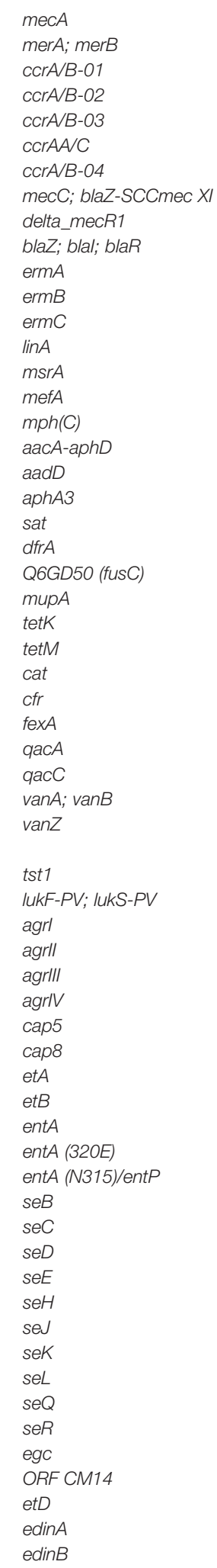




$\begin{array}{lcc} & \text { \# positive } \mathbf{( N ~ = ~ 1 2 9 )} & \text { \% positive } \\ \text { edinC } & 1 & 0.8 \\ \text { ACME } & 2 & 1.6 \\ \text { sasG } & 82 & 63.6\end{array}$

to these infections. These strains include CC1-MRSA-[IV+fusC $+c c r A B 1]$ which has previously been described in Western Australia as well as in the UAE and Saudi Arabia (Coombs et al., 2006; Raji et al., 2016; Senok et al., 2020a). It has also been detected in Pakistan (unpublished observation/personal communication, Dr B. Jamil, BJ Micro Lab (SMC Private) Limited, Pakistan and Dr. A. Syed, University of Haripur, Pakistan), a country with dynamic population movement to Arabian Gulf countries. The CC5 strains include CC5-MRSAIV (PVL+/edinA+) which has been reported in the Arabian Gulf as well as in Australia, where it is, dubbed WA MRSA-121 (Riley and Rouse, 1995; Dailey et al., 2005; Bloomfield et al., 2020). The CC5-MRSA-[V/VT+fusC] was found four times; one isolate was subtyped and yielded SCCmec V rather than VT. This strain which appears to be common in this region was sporadically found in Australia (WA MRSA-109) (Coombs et al., 2012; Senok et al., 2020a). The CC5-MRSA-[V/VT+fusC] (PVL+) has been identified sporadically at the Gulf and in Australia (Senok et al., 2020a). The CC6-MRSA-IV is common in the Middle East and has also been found in Europe among refugees of Middle Eastern origin (Monecke et al., 2011a; Monecke et al., 2012b; Kossow et al., 2018; Bartels et al., 2021) as well as in Australia.

CC8-MRSA-[IV+ACME] (PVL+), USA300 is a well-known community-acquired pandemic MRSA strain which is abundant in North America and sporadic in Western Europe but was recently observed in Pakistan and Afghanistan (Monecke et al., 2011a). In the UAE, novel variants of this MRSA strain and putative PVL-deletion mutants have been reported (Senok et al., 2020a). For CC15-MRSA-[V+fusC] the ancestral CC15-MSSA is a common nasal colonizer in the Middle East (Sarkar et al., 2016; Senok et al., 2018). However, in recent years, CC15-MRSA has emerged among humans and livestock (camels) in the UAE, Kuwait and Saudi Arabia (Raji et al., 2016; Senok et al., 2017; Boswihi et al., 2018; Senok et al., 2020a). CC22-MRSA are prevalent in the Arabian Gulf region and six distinct 'strains' of CC22-MRSA-IV have been reported (Senok et al., 2016b). Whilst CC22-MRSA-IV (PVL+) are common in the Middle East, they occur sporadically in other regions. CC22-MRSA-IV (PVL+/ $t s t+$ ) was apparently first observed in Iran (Goudarzi et al., 2017) and spread to other Gulf countries as well as far as to Nepal (Roberts et al., 2018; Roberts et al., 2020). The recent identification of CC22-MRSA-[IV $+f u s C+c c r A A /(C)$ which harbored a novel SCCmec element is indicative of the expansion of the diversity of CC22-MRSA in the region (Senok et al., 2020a). CC30-MRSA-IV (PVL+) also known as "WSPP/ Southwest Pacific Clone" was first described from Australia and Pacific islands (Monecke et al., 2011a). However, there are different variants with different SCCmec subtypes, and this might indicate a polyphyletic origin, i.e., multiple acquisitions of SCCmec elements by ancestral CC30 MSSA. This is not fully understood and might warrant further study. However, the CC30-MRSA-[VI+fusC] (PVL+) detected in this study appears to be uncommon and restricted to the Arabian Gulf region (Senok et al., 2019a).

CC80-MRSA-IV (PVL+) was frequently dubbed the "European Clone" of community-acquired MRSA but recently it emerged in the Maghreb countries (Algeria, Tunisia) and Lebanon from where the possibility of dissemination to Arabian Gulf countries is feasible due frequent travel (Kechrid et al., 2011; Djoudi et al., 2013; Basset et al., 2015).

CC97-MRSA-[V +fusC] is a Middle Eastern strain observed in Saudi Arabia and the UAE (Senok et al., 2016a; Senok et al., 2020a). However, sporadic cases from Western Europe have been reported as well as an outbreak in Ireland which was linked to an Egyptian connection (Mcmanus et al., 2021). CC121MRSA-V/VT (PVL+) are rare in the UAE (Senok et al., 2020a) and elsewhere. Another rare strain is CC152-MRSA-IV (PVL+) which had previously been observed in Kuwait (Boswihi et al., 2018). CC398-MRSA-V/VT (PVL+) is related to the European livestock strain. However, the PVL-positive lineage has no livestock connection, and it is known to occur in South-East Asia (Yu et al., 2008; Moller et al., 2019). Indeed, cases of infections and outbreaks associated with this CC398-MRSA in Europe were linked to South-East Asia (Moller et al., 2019; Nurjadi et al., 2019). The first identification of this strain in the Middle East region was recently reported in the UAE, possibly introduced via South-East Asia or Europe (Senok et al., 2020a). CC772-MRSA-V (PVL+), "Bengal Bay Clone" is a pandemic, multi-resistant and virulent strain emerging from the Indian subcontinent (i.e., India, Bangladesh, Pakistan) (Ellington et al., 2010; Steinig et al., 2019). Given the high number of people from these countries working in the region, its occurrence is not surprising, and indeed, it has been observed in many studies from the region (Monecke et al., 2012a; Udo et al., 2014; Boswihi et al., 2016; Senok et al., 2020b). CC1153-MRSA[V/VT+fusC] (PVL+) and CC1153-MRSA-PseudoSCCmec [class $\mathrm{B}+f u s C+c c r A B 1](\mathrm{PVL}+)$ are both strains that are known to occur mainly in Gulf countries (Monecke et al., 2021).

With regards to MSSA, a wide variety of different strains was found including some rare and poorly characterized lineages such as CC1156, CC2531, CC2867, CC2990 and S. argenteus CC2596. The most common $p v l^{+v e}$ MSSA strain was CC152MSSA (7 isolates), a lineage previously known to occur in Western Africa and Trinidad \& Tobago (Ruimy et al., 2008; Monecke et al., 2014; Okuda et al., 2016; Obasuyi et al., 2020).

In conclusion, we demonstrate excellent diagnostic accuracy indices for a novel lateral flow immunoassay for rapid 
identification of PVL in MSSA/MRSA identified from cultures of SSTI in a setting with high prevalence of $p v l^{+v e}$ strains. These findings support the introduction of this test for routine use in the diagnostic microbiology laboratory especially in settings where facilities for molecular assays are lacking. The prevalence and diversity of MRSA strains associated with SSTIs as well as the high occurrence of $p v l$ and fusC genes in these strains is of concern.

\section{DATA AVAILABILITY STATEMENT}

The raw data supporting the conclusions of this article will be made available by the authors, without undue reservation.

\section{ETHICS STATEMENT}

The studies involving human participants were reviewed and approved by Mohammed Bin Rashid University and Mediclinic Hospitals ethics committees (MBRU-IRB-2020-003 and MCME.CR.98.MCIT.2020). Written informed consent for participation was not required for this study in accordance with the national legislation and the institutional requirements.

\section{REFERENCES}

Abdulgader, S. M., Shittu, A. O., Nicol, M. P., and Kaba, M. (2015). Molecular Epidemiology of Methicillin-Resistant Staphylococcus Aureus in Africa: A Systematic Review . Front. Microbiol. 6. doi: 10.3389/fmicb.2015.00348

Badiou, C., Dumitrescu, O., George, N., Forbes, A. R., Drougka, E., Chan, K. S., et al. (2010). Rapid Detection of Staphylococcus Aureus Panton-Valentine Leukocidin in Clinical Specimens by Enzyme-Linked Immunosorbent Assay and Immunochromatographic Tests. J. Clin. Microbiol. 48, 1384-1390. doi: 10.1128/JCM.02274-09

Bartels, M. D., Worning, P., Andersen, L. P., Bes, M., Enger, H., As, C. G., et al. (2021). Repeated Introduction and Spread of the MRSA Clone t304/ST6 in Northern Europe. Clin. Microbiol. Infect. 27, 284 e281-284 e285. doi: 10.1016/j.cmi.2020.05.004

Basset, P., Amhis, W., and Blanc, D. S. (2015). Changing Molecular Epidemiology of Methicillin-Resistant Staphylococcus Aureus in an Algerian Hospital. J. Infect. Dev. Ctries 9, 206-209. doi: 10.3855/jidc.4620

Bloomfield, L. E., Coombs, G. W., Tempone, S., and Armstrong, P. K. (2020). Marked Increase in Community-Associated Methicillin-Resistant Staphylococcus Aureus Infections, Western Australia 2004-2018. Epidemiol. Infection 148, e153-e153. doi: 10.1017/S0950268820000849

Boakes, E., Kearns, A. M., Ganner, M., Perry, C., Hill, R. L., and Ellington, M. J. (2011). Distinct Bacteriophages Encoding Panton-Valentine Leukocidin (PVL) Among International Methicillin-Resistant Staphylococcus Aureus Clones Harboring PVL. J. Clin. Microbiol. 49, 684-692. doi: 10.1128/JCM.01917-10

Boswihi, S. S., Udo, E. E., and Al-Sweih, N. (2016). Shifts in the Clonal Distribution of Methicillin-Resistant Staphylococcus Aureus in Kuwait Hospitals: 19922010. PloS One 11, e0162744. doi: 10.1371/journal.pone.0162744

Boswihi, S. S., Udo, E. E., Monecke, S., Mathew, B., Noronha, B., Verghese, T., et al. (2018). Emerging Variants of Methicillin-Resistant Staphylococcus Aureus Genotypes in Kuwait Hospitals. PloS One 13, e0195933. doi: 10.1371/ journal.pone.0195933

CLSI (2017). Performance Standards for Antimicrobial Susceptibility Testing. 27th ed. CLSI supplement M100. Wayne, PA: Clinical and Laboratory Standards Institute.

Coombs, G., Pearson, J., Nimmo, G., and Christiansen, K. (2012). Staphylococcus Aureus Program 2011 (SAP2011) Hospital Onset Survey MRSA Epidemiology

\section{AUTHOR CONTRIBUTIONS}

Conceptualization, AS, SM, and RE. Data curation, AS, SM, RN, HC, ST, EM, and RE. Formal analysis, AS, SM, and RE. Investigation, RN, HC, ST, and EM. Methodology, AS, SM, RN, HC, ST, EM, and RE. Project administration, AS, SM, and RN. Resources, AS, SM, and RE. Writing - original draft, AS, SM, and RE. All authors contributed to the article and approved the submitted version.

\section{FUNDING}

We acknowledge the German Federal Ministry for Economic Affairs and Energy for supporting the development of the PVL antibodies and of the rapid assay within the framework of the INNO-KOM project (49MF180153).

\section{ACKNOWLEDGMENTS}

We acknowledge the support of Anne-Marie Gad, Friedrich Scholz (Senova $\mathrm{GmbH}$ ) and Peter Miethe (FZMB Gmbh) for the supply of the PVL antibodies and the lateral flow immunoassay. We acknowledge the support of Mohammed Bin Rashid University of Medicine and Health Sciences, Dubai, UAE and Aljalila Foundation, Dubai UAE.

and Typing Report. Prepared on Behalf of the Australian Group for Antimicrobial Resistance (AGAR). Available at: https://agargroup.org.au/wpcontent/uploads/2017/08/SAP11-MRSA-TYPING-REPORT-FINALPROTECTED.pdf (Accessed 4th August 2021).

Coombs, G. W., Pearson, J. C., O'brien, F. G., Murray, R. J., Grubb, W. B., and Christiansen, K. J. (2006). Methicillin-Resistant Staphylococcus Aureus Clones, Western Australia. Emerg Infect. Dis. 12, 241-247. doi: 10.3201/ eid1202.050454

Dailey, L., Coombs, G. W., O'brien, F. G., Pearman, J. W., Christiansen, K., Grubb, W. B., et al. (2005). Methicillin-Resistant Staphylococcus Aureus, Western Australia. Emerg Infect. Dis. 11, 1584-1590. doi: 10.3201/eid1110.050125

Djoudi, F., Bonura, C., Benallaoua, S., Touati, A., Touati, D., Aleo, A., et al. (2013). Panton-Valentine Leukocidin Positive Sequence Type 80 Methicillin-Resistant Staphylococcus Aureus Carrying a Staphylococcal Cassette Chromosome Mec Type IVc is Dominant in Neonates and Children in an Algiers Hospital. New Microbiol. 36, 49-55.

Ellington, M. J., Ganner, M., Warner, M., Cookson, B. D., and Kearns, A. M. (2010). Polyclonal Multiply Antibiotic-Resistant Methicillin-Resistant Staphylococcus Aureus With Panton-Valentine Leucocidin in England. J. Antimicrob. Chemother. 65, 46-50. doi: 10.1093/jac/dkp386

Gillet, Y., Dumitrescu, O., Tristan, A., Dauwalder, O., Javouhey, E., Floret, D., et al. (2011). Pragmatic Management of Panton-Valentine Leukocidin-Associated Staphylococcal Diseases. Int. J. Antimicrob. Agents 38, 457-464. doi: 10.1016/ j.ijantimicag.2011.05.003

Gillet, Y., Tristan, A., Rasigade, J. P., Saadatian-Elahi, M., Bouchiat, C., Bes, M., et al. (2021). Prognostic Factors of Severe Community-Acquired Staphylococcal Pneumonia in France. Eur. Respir. J 2004445. doi: 10.1183/13993003.04445-20201

Gosbell, I. B. (2005). Epidemiology, Clinical Features and Management of Infections Due to Community Methicillin-Resistant Staphylococcus Aureus (cMRSA). Intern. Med. J. 35 Suppl 2, S120-S135. doi: 10.1111/j.1444-0903.2005.00985.x

Goudarzi, M., Bahramian, M., Satarzadeh Tabrizi, M., Udo, E. E., Figueiredo, A. M., Fazeli, M., et al. (2017). Genetic Diversity of Methicillin Resistant Staphylococcus Aureus Strains Isolated From Burn Patients in Iran: ST239SCCmec III/t037 Emerges as the Major Clone. Microb. Pathog. 105, 1-7. doi: 10.1016/j.micpath.2017.02.004 
Kaneko, J., and Kamio, Y. (2004). Bacterial Two-Component and HeteroHeptameric Pore-Forming Cytolytic Toxins: Structures, Pore-Forming Mechanism, and Organization of the Genes. Biosci. Biotechnol. Biochem. 68, 981-1003. doi: 10.1271/bbb.68.981

Kechrid, A., Pérez-Vázquez, M., Smaoui, H., Hariga, D., Rodríguez-Baños, M., Vindel, A., et al. (2011). Molecular Analysis of Community-Acquired MethicillinSusceptible and Resistant Staphylococcus Aureus Isolates Recovered From Bacteraemic and Osteomyelitis Infections in Children From Tunisia. Clin. Microbiol. Infect. 17, 1020-1026. doi: 10.1111/j.1469-0691.2010.03367.x

Köhler, G., and Milstein, C. (2005). Continuous Cultures of Fused Cells Secreting Antibody of Predefined Specificity. 1975. J. Immunol. 174, 2453-2455. doi: $10.1038 / 256495 \mathrm{a} 0$

Kossow, A., Stuhmer, B., Schaumburg, F., Becker, K., Glatz, B., Mollers, M., et al. (2018). High Prevalence of MRSA and Multi-Resistant Gram-Negative Bacteria in Refugees Admitted to the Hospital-But No Hint of Transmission. PloS One 13, e0198103. doi: 10.1371/journal.pone.0198103

Marazza, G., Harbarth, S., and Borradori, L. (2007). [Serious Staphylococcus Aureus Skin Infections That are Panton-Valentine Leukocidin Positive: A New Challenge]. Rev. Med. Suisse 3 1106-1108, 1110-1101.

Masiuk, H., Kopron, K., Grumann, D., Goerke, C., Kolata, J., Jursa-Kulesza, J., et al. (2010). Association of Recurrent Furunculosis With Panton-Valentine Leukocidin and the Genetic Background of Staphylococcus Aureus. J. Clin. Microbiol. 48, 1527-1535. doi: 10.1128/JCM.02094-09

Mcmanus, B. A., Aloba, B. K., Earls, M. R., Brennan, G. I., O'connell, B., Monecke, S., et al. (2021). Multiple Distinct Outbreaks of Panton-Valentine LeucocidinPositive Community-Associated Meticillin-Resistant Staphylococcus Aureus in Ireland Investigated by Whole-Genome Sequencing. J. Hosp. Infect. 108, 7280. doi: 10.1016/j.jhin.2020.11.021

Moller, J. K., Larsen, A. R., Ostergaard, C., Moller, C. H., Kristensen, M. A., and Larsen, J. (2019). International Travel as Source of a Hospital Outbreak With an Unusual Meticillin-Resistant Staphylococcus Aureus Clonal Complex 398, Denmark 2016. Euro Surveill 24 (42), pii=1800680. doi: 10.2807/1560-7917.ES.2019.24.42.1800680

Monecke, S., Coombs, G., Shore, A. C., Coleman, D. C., Akpaka, P., Borg, M., et al. (2011a). A Field Guide to Pandemic, Epidemic and Sporadic Clones of Methicillin-Resistant Staphylococcus Aureus. PloS One 6, e17936. doi: 10.1371/journal.pone.0017936

Monecke, S., Ehricht, R., Slickers, P., Wernery, R., Johnson, B., Jose, S., et al. (2011b). Microarray-Based Genotyping of Staphylococcus Aureus Isolates From Camels. Vet. Microbiol. 150, 309-314. doi: 10.1016/j.vetmic.2011.02.001

Monecke, S., Jatzwauk, L., Muller, E., Nitschke, H., Pfohl, K., Slickers, P., et al. (2016). Diversity of SCCmec Elements in Staphylococcus Aureus as Observed in SouthEastern Germany. PloS One 11, e0162654. doi: 10.1371/journal.pone.0162654

Monecke, S., Muller, E., Braun, S. D., Armengol-Porta, M., Bes, M., Boswihi, S., et al. (2021). Characterisation of S. Aureus/MRSA CC1153 and Review of Mobile Genetic Elements Carrying the Fusidic Acid Resistance Gene fusC. Sci. Rep. 11, 8128. doi: 10.1038/s41598-021-86273-4

Monecke, S., Müller, E., Buechler, J., Rejman, J., Stieber, B., Akpaka, P. E., et al. (2013). Rapid Detection of Panton-Valentine Leukocidin in Staphylococcus Aureus Cultures by Use of a Lateral Flow Assay Based on Monoclonal Antibodies. J. Clin. Microbiol. 51, 487-495. doi: 10.1128/JCM.02285-12

Monecke, S., Nitschke, H., Slickers, P., Ehricht, R., Swanston, W., Manjunath, M., et al. (2012a). Molecular Epidemiology and Characterisation of MRSA Isolates From Trinidad and Tobago. Eur. J. Clin. Microbiol. Infect. Dis. 31, 1497-1500. doi: 10.1007/s10096-011-1469-6

Monecke, S., Skakni, L., Hasan, R., Ruppelt, A., Ghazal, S. S., Hakawi, A., et al. (2012b). Characterisation of MRSA Strains Isolated From Patients in a Hospital in Riyadh, Kingdom of Saudi Arabia. BMC Microbiol. 12, 146. doi: 10.1186/1471-2180-12-146

Monecke, S., Slickers, P., Ellington, M. J., Kearns, A. M., and Ehricht, R. (2007). High Diversity of Panton-Valentine Leukocidin-Positive, MethicillinSusceptible Isolates of Staphylococcus Aureus and Implications for the Evolution of Community-Associated Methicillin-Resistant S. Aureus. Clin. Microbiol. Infect. 13, 1157-1164. doi: 10.1111/j.1469-0691.2007.01833.x

Monecke, S., Stieber, B., Roberts, R., Akpaka, P. E., Slickers, P., and Ehricht, R. (2014). Population Structure of Staphylococcus Aureus From Trinidad \& Tobago. PloS One 9, e89120. doi: 10.1371/journal.pone.0089120

Narita, S., Kaneko, J., Chiba, J., Piemont, Y., Jarraud, S., Etienne, J., et al. (2001). Phage Conversion of Panton-Valentine Leukocidin in Staphylococcus Aureus:
Molecular Analysis of a PVL-Converting Phage, phiSLT. Gene 268, 195-206. doi: 10.1016/S0378-1119(01)00390-0

Nurjadi, D., Fleck, R., Lindner, A., Schafer, J., Gertler, M., Mueller, A., et al. (2019). Import of Community-Associated, Methicillin-Resistant Staphylococcus Aureus to Europe Through Skin and Soft-Tissue Infection in Intercontinental Traveller-2016. Clin. Microbiol. Infect. 25,739-746. doi: 10.1016/j.cmi.2018.09.023

O'hara, F. P., Guex, N., Word, J. M., Miller, L. A., Becker, J. A., Walsh, S. L., et al. (2008). A Geographic Variant of the Staphylococcus Aureus Panton-Valentine Leukocidin Toxin and the Origin of Community-Associated MethicillinResistant S. Aureus USA300. J. Infect. Dis. 197, 187-194. doi: 10.1086/524684 Obasuyi, O., Mcclure, J., Oronsaye, F. E., Akerele, J. O., Conly, J., and Zhang, K. (2020). Molecular Characterization and Pathogenicity of Staphylococcus Aureus Isolated From Benin-City, Nigeria. Microorganisms 8 (6), 912. doi: 10.3390/microorganisms 8060912

Okuda, K. V., Toepfner, N., Alabi, A. S., Arnold, B., Bélard, S., Falke, U., et al. (2016). Molecular Epidemiology of Staphylococcus Aureus From Lambaréné, Gabon. Eur. J. Clin. Microbiol. Infect. Dis. 35, 1963-1973. doi: 10.1007/s10096016-2748-z

Olaniyi, R., Pozzi, C., Grimaldi, L., and Bagnoli, F. (2017). Staphylococcus AureusAssociated Skin and Soft Tissue Infections: Anatomical Localization, Epidemiology, Therapy and Potential Prophylaxis. Curr. Top. Microbiol. Immunol. 409, 199-227. doi: 10.1007/82_2016_32

Public Health England (2008). Guidance on the Diagnosis and Management of PVL-Associated Staphylococcus Aureus Infections (PVL-SA) in England; Prepared by PVL Sub-Group of the Steering Group on Healthcare Associated Infection. Available at: https://www.gov.uk/government/publications/pvlstaphylococcus-aureus-infections-diagnosis-and-management (Accessed 4th August 2021).

Raji, M. A., Garaween, G., Ehricht, R., Monecke, S., Shibl, A. M., and Senok, A. (2016). Genetic Characterization of Staphylococcus Aureus Isolated From Retail Meat in Riyadh, Saudi Arabia. Front. Microbiol. 7, 911. doi: 10.3389/ fmicb.2016.00911

Ramakrishnan, K., Salinas, R. C., and Agudelo Higuita, N. I. (2015). Skin and Soft Tissue Infections. Am. Fam Physician 92, 474-483.

Rasigade, J. P., Laurent, F., Lina, G., Meugnier, H., Bes, M., Vandenesch, F., et al. (2010). Global Distribution and Evolution of Panton-Valentine LeukocidinPositive Methicillin-Susceptible Staphylococcus aureus, 1981-2007. J. Infect. Dis. 201, 1589-1597. doi: 10.1086/652008

Rasigade, J. P., Trouillet-Assant, S., Breurec, S., Antri, K., Lina, G., Bes, M., et al. (2015). The Levels of Antibodies to Panton-Valentine Leukocidin (PVL) Vary With PVL Prevalence Along a North-to-South Gradient. Eur. J. Clin. Microbiol. Infect. Dis. 34, 927-933. doi: 10.1007/s10096-014-2307-4

Riley, T. V., and Rouse, I. L. (1995). Methicillin-Resistant Staphylococcus Aureus in Western Australi-1992. J. Hosp Infect. 29, 177-188. doi: 10.1016/0195-6701 (95) $90327-5$

Roberts, M. C., Joshi, P. R., Greninger, A. L., Melendez, D., Paudel, S., Acharya, M., et al. (2018). The Human Clone ST22 SCCmec IV Methicillin-Resistant Staphylococcus Aureus Isolated From Swine Herds and Wild Primates in Nepal: Is Man the Common Source? FEMS Microbiol. Ecol. 94 (5), fiy052. doi: $10.1093 /$ femsec/fiy052

Roberts, M. C., Joshi, P. R., Monecke, S., Ehricht, R., Muller, E., Gawlik, D., et al. (2020). Staphylococcus Aureus and Methicillin Resistant S. Aureus in Nepalese Primates: Resistance to Antimicrobials, Virulence, and Genetic Lineages. Antibiotics (Basel) 9 (10), 689. doi: 10.3390/antibiotics9100689

Ruimy, R., Maiga, A., Armand-Lefevre, L., Maiga, I., Diallo, A., Koumaré, A. K., et al. (2008). The Carriage Population of Staphylococcus Aureus From Mali is Composed of a Combination of Pandemic Clones and the Divergent PantonValentine Leukocidin-Positive Genotype ST152. J. Bacteriol. 190, 3962-3968. doi: 10.1128/JB.01947-07

Sarkar, A., Raji, A., Garaween, G., Soge, O., Rey-Ladino, J., Al-Kattan, W., et al. (2016). Antimicrobial Resistance and Virulence Markers in Methicillin Sensitive Staphylococcus Aureus Isolates Associated With Nasal Colonization. Microb. Pathog. 93, 8-12. doi: 10.1016/j.micpath.2016.01.008

Senok, A., Ehricht, R., Monecke, S., Al-Saedan, R., and Somily, A. (2016a). Molecular Characterization of Methicillin-Resistant Staphylococcus Aureus in Nosocomial Infections in a Tertiary-Care Facility: Emergence of New Clonal Complexes in Saudi Arabia. New Microbes New Infect. 14, 13-18. doi: 10.1016/ j.nmni.2016.07.009 
Senok, A., Nassar, R., Celiloglu, H., Nabi, A., Alfaresi, M., Weber, S., et al. (2020a). Genotyping of Methicillin Resistant Staphylococcus Aureus From the United Arab Emirates. Sci. Rep. 10, 18551. doi: 10.1038/s41598-020-75565-w

Senok, A., Nassar, R., Kaklamanos, E. G., Belhoul, K., Abu Fanas, S., Nassar, M., et al. (2020b). Molecular Characterization of Staphylococcus Aureus Isolates Associated With Nasal Colonization and Environmental Contamination in Academic Dental Clinics. Microb. Drug Resist. 26, 661-669. doi: 10.1089/mdr.2019.0318

Senok, A., Slickers, P., Hotzel, H., Boswihi, S., Braun, S. D., Gawlik, D., et al. (2019a). Characterisation of a Novel SCCmec VI Element Harbouring fusC in an Emerging Staphylococcus Aureus Strain From the Arabian Gulf Region. PloS One 14, e0223985. doi: 10.1371/journal.pone.0223985

Senok, A., Somily, A. M., Nassar, R., Garaween, G., Kim Sing, G., Muller, E., et al. (2019b). Emergence of Novel Methicillin-Resistant Staphylococcus Aureus Strains in a Tertiary Care Facility in Riyadh, Saudi Arabia. Infect. Drug Resist. 12, 2739-2746. doi: 10.2147/IDR.S218870

Senok, A., Somily, A., Raji, M., Garaween, G., Kabil, M., Shibl, A., et al. (2018). Genotyping of Staphylococcus Aureus Associated With Nasal Colonization Among Healthcare Workers Using DNA Microarray. J. Infect. Dev. Ctries 12, 321-325. doi: 10.3855/jidc.10328

Senok, A., Somily, A., Raji, A., Gawlik, D., Al-Shahrani, F., Baqi, S., et al. (2016b). Diversity of Methicillin-Resistant Staphylococcus Aureus CC22-MRSA-IV From Saudi Arabia and the Gulf Region. Int. J. Infect. Dis. 51, 31-35. doi: 10.1016/j.ijid.2016.08.016

Senok, A. C., Somily, A. M., Slickers, P., Raji, M. A., Garaween, G., Shibl, A., et al. (2017). Investigating a Rare Methicillin-Resistant Staphylococcus Aureus Strain: First Description of Genome Sequencing and Molecular Characterization of CC15-MRSA. Infect. Drug Resist. 10, 307-315. doi: 10.2147/IDR.S145394

Shallcross, L. J., Fragaszy, E., Johnson, A. M., and Hayward, A. C. (2013). The Role of the Panton-Valentine Leucocidin Toxin in Staphylococcal Disease: A Systematic Review and Meta-Analysis. Lancet Infect. Dis. 13, 43-54. doi: 10.1016/S1473-3099(12)70238-4

Steinig, E. J., Duchene, S., Robinson, D. A., Monecke, S., Yokoyama, M., Laabei, M., et al. (2019). Evolution and Global Transmission of a Multidrug-Resistant, CommunityAssociated Methicillin-Resistant Staphylococcus Aureus Lineage From the Indian Subcontinent. mBio 10 (6), e01105-19. doi: 10.1128/mBio.01105-19

Stieber, B., Monecke, S., Müller, E., Baier, V., W. Coombs, G., and Ehricht, R. (2014). Development and Usage of Protein Microarrays for the Quantitative Measurement of Panton-Valentine Leukocidin. Mol. Cell. Probes 28, 123-132. doi: 10.1016/j.mcp.2013.11.003
Szmigielski, S., Sobiczewska, E., Prevost, G., Monteil, H., Colin, D. A., and Jeljaszewicz, J. (1998). Effect of Purified Staphylococcal Leukocidal Toxins on Isolated Blood Polymorphonuclear Leukocytes and Peritoneal Macrophages In Vitro. Zentralbl. Bakteriol. 288, 383-394. doi: 10.1016/S0934-8840(98)80012-1

Udo, E. E., Al-Lawati, B. A., Al-Muharmi, Z., and Thukral, S. S. (2014). Genotyping of Methicillin-Resistant Staphylococcus Aureus in the Sultan Qaboos University Hospital, Oman Reveals the Dominance of PantonValentine Leucocidin-Negative ST6-IV/t304 Clone. New Microbes New Infect. 2, 100-105. doi: 10.1002/nmi2.47

Wannet, W. J., Spalburg, E., Heck, M. E., Pluister, G. N., Tiemersma, E., Willems, R. J., et al. (2005). Emergence of Virulent Methicillin-Resistant Staphylococcus Aureus Strains Carrying Panton-Valentine Leucocidin Genes in The Netherlands. J. Clin. Microbiol. 43, 3341-3345. doi: 10.1128/JCM.43.7.3341-3345.2005

Yamasaki, O., Kaneko, J., Morizane, S., Akiyama, H., Arata, J., Narita, S., et al. (2005). The Association Between Staphylococcus Aureus Strains Carrying Panton-Valentine Leukocidin Genes and the Development of Deep-Seated Follicular Infection. Clin. Infect. Dis. 40, 381-385. doi: 10.1086/427290

Yu, F., Chen, Z., Liu, C., Zhang, X., Lin, X., Chi, S., et al. (2008). Prevalence of Staphylococcus Aureus Carrying Panton-Valentine Leukocidin Genes Among Isolates From Hospitalised Patients in China. Clin. Microbiol. Infect. 14, $381-$ 384. doi: 10.1111/j.1469-0691.2007.01927.x

Conflict of Interest: The authors declare that the research was conducted in the absence of any commercial or financial relationships that could be construed as a potential conflict of interest.

Publisher's Note: All claims expressed in this article are solely those of the authors and do not necessarily represent those of their affiliated organizations, or those of the publisher, the editors and the reviewers. Any product that may be evaluated in this article, or claim that may be made by its manufacturer, is not guaranteed or endorsed by the publisher.

Copyright (c) 2021 Senok, Monecke, Nassar, Celiloglu, Thyagarajan, Müller and Ehricht. This is an open-access article distributed under the terms of the Creative Commons Attribution License (CC BY). The use, distribution or reproduction in other forums is permitted, provided the original author(s) and the copyright owner(s) are credited and that the original publication in this journal is cited, in accordance with accepted academic practice. No use, distribution or reproduction is permitted which does not comply with these terms. 